\title{
A systematic review and meta-analysis of the timing of indwelling catheter extubation in patients undergoing gynecological and obstetric surgery
}

\author{
Xin $\operatorname{Liao}^{1,2,3}, \mathrm{Li} \mathrm{Xie}^{1,2,3}$ \\ ${ }^{1}$ Department of Operating Room, West China Second University Hospital, Sichuan University, Chengdu, China; ${ }^{2}$ West China School of Nursing, \\ Sichuan University, Chengdu, China; ${ }^{3}$ Key Laboratory of Birth Defects and Related Diseases of Women and Children, Sichuan University, Ministry \\ of Education, Chengdu, China \\ Contributions: (I) Conception and design: Both authors; (II) Administrative support: L Xie; (III) Provision of study materials or patients: X Liao; (IV) \\ Collection and assembly of data: X Liao; (V) Data analysis and interpretation: X Liao; (VI) Manuscript writing: Both authors; (VII) Final approval of \\ manuscript: Both authors. \\ Correspondence to: Li Xie. Department of Operating Room, West China Second University Hospital, Sichuan University/West China School of \\ Nursing, Sichuan University/Key Laboratory of Birth Defects and Related Diseases of Women and Children (Sichuan University), Ministry of \\ Education, Chengdu 610041, China. Email: xieli2360@163.com.
}

Background: The timing of urinary catheter removal after gynecological and obstetric surgery remains controversial. This meta-analysis investigated the optimal timing of urinary catheter removal.

Methods: The PubMed, Ovid Medline, Cochrane, and Embase databases were searched for literatures published between 2010 and 2021 relating to randomized controlled studies examining the timing of catheter removal. The modified Joanna Briggs Institute (JBI) scoring criteria was used to assess the quality of the literatures. After extracting the literature data, the Revman 5.3 software was used for analysis and to obtain the statistical forest plots.

Results: A total of 345 literatures were screened and 11 literatures were finally included. Meta-analysis showed that there was no statistical difference in the occurrence of urinary tract infection (UTI) rate between extubation at 6 hours and immediately after surgery [odds ratio $(\mathrm{OR})=1.66$; $95 \%$ confidence interval (CI): 0.58 to $4.81 ; \mathrm{P}=0.35$ ], but the urinary retention rate was significantly lower in patients who were extubated at 6 hours post-surgery compared to immediately after surgery ( $\mathrm{OR}=0.06 ; 95 \% \mathrm{CI}$ : 0.01 to $0.36 ; \mathrm{P}=0.002)$. In patients who were extubated at 12 hours post-operation, the rate of UTI was significantly higher than immediate extubation post-operation ( $\mathrm{OR}=2.32$; $95 \% \mathrm{CI}$ : 1.31 to $4.10 ; \mathrm{P}=0.004$ ), while the probability of urinary retention was significantly lower than extubated immediate $(\mathrm{OR}=0.18 ; 95 \% \mathrm{CI}$ : 0.04 to 0.83 ; $\mathrm{P}=0.03)$. Similarly, in patients who were extubated at 24 hours post-operation, the UTI rate was significantly higher than that patients who were immediately extubated ( $\mathrm{OR}=4.51 ; 95 \% \mathrm{CI}: 2.02$ to $10.09 ; \mathrm{P}=0.0002)$ and the urinary retention rate was significantly lower than extubated immediately (OR $=0.06 ; 95 \%$ CI: 0.01 to $0.32 ; \mathrm{P}=0.001)$. The UTI rate of patients who were extubated 48 hours after surgery was not significantly different from that of patients extubated 24 hours after surgery $(\mathrm{OR}=1.62 ; 95 \% \mathrm{CI}$ : 0.76 to $3.45 ; \mathrm{P}=0.21$ ) and the incidence of urinary retention was not significantly different $(\mathrm{OR}=0.28 ; 95 \% \mathrm{CI}: 0.07$ to 1.18 ; $\mathrm{P}=0.08$ ).

Discussion: The optimal time for removal of the urinary catheter is 6 hours after gynecological and obstetric surgery.

Keywords: Gynecological and obstetric surgery; indwelling catheter; catheter removal; meta-analysis

Submitted Oct 21, 2021. Accepted for publication Dec 06, 2021.

doi: 10.21037/apm-21-3290

View this article at: https://dx.doi.org/10.21037/apm-21-3290 


\section{Introduction}

Indwelling catheters are a routine procedure in gynecological and obstetric surgery, the purpose of which is to avoid accumulation of urine in the bladder, maintain a clear view during surgery, and avoid intraoperative injury to other tissues $(1,2)$. In addition, indwelling catheters can reduce postoperative urinary retention and reduce associated long-term urinary system diseases such as bladder weakness and dysuria (3). However, over an extended period of time, indwelling catheters can lead to bacterial colonization in the bladder and urinary tract infections (UTIs) (4). Some researchers have suggested that urinary catheters should be removed immediately after surgery when it is no longer needed so as to reduce the risk of asymptomatic bacteriuria and UTIs (5). However, others suggested that extubation immediately after hysterectomy can reduce the pain caused by indwelling catheter, but will increase the incidence of dysuria (6). The timing of urinary catheter removal remains controversial, in a meta-analysis conducted by Huang et al. (7), the author compared UTI rates for the timing of $\leq 6$ hours and $>6$ hours removal and concluded that removal time at $\leq 6$ hours was more beneficial, but the conclusion with low quality because it didn't cover other timings except 6 hours. In our meta-analysis, we dived into more precise timings as 6, 12, 24, 48 hours, and combined relevant studies in recent years to determine the optimal time for removal of urinary catheters. We present the following article in accordance with the PRISMA reporting checklist (available at https://dx.doi.org/10.21037/apm-21-3290).

\section{Methods}

\section{Literature search}

The PubMed, Ovid Medline, Cochrane, and Embase databases were searched for published literature relating to the timing of indwelling catheter extubation in obstetrics and gynecology. We only covered these databases because we considered papers from these databases have better quality.

The following terms were used for keyword searches, either alone or in combination: "indwelling urinary catheter", "extubation/removal", "timing/duration", "postoperative", and "gynecology". The publication period was limited to 2010 and 2021, and the literature type was restricted to randomized controlled trials (RCTs).

Studies were included if the following criteria were satisfied: (I) patients aged 18 years and over were treated in an obstetrics and gynecology department; (II) the patients were assigned according to random sequence to 2 or more random groups in which the timing of postoperative indwelling catheter extubation was either 0 hours after the operation (immediate extubation), or 6, 12, 24 or 48 hours after the operation; (III) the outcome measures included at least 1 indicator such as incidence of UTI, urinary retention rate (UR), length of hospital stay, pain level, comfort level, or bacteriuria rate. The criteria for assessing UTIs included the following: the presence of symptoms such as frequent urination, dysuria, burning sensation on urination, and dysuria; and the presence of bacterial infection on urine specimen examination.

The following literatures were excluded: (I) observational literatures, review articles, individual case reports, investigations, systematic reviews, experience summaries, report literatures; and (II) literatures lacking outcome measures or incomplete data.

The literatures were screened independently by two researchers. Abstracts and full-text articles were reviewed. In the case of duplicate literatures, the more recently published study with greater comprehensive outcome measures was selected. Articles that met the criteria were included according to the inclusion and exclusion criteria.

\section{Quality and bias evaluation of the literatures}

The quality of the included literatures was assessed using the modified Joanna Briggs Institute (JBI) scoring criteria (6) for RCTs. The ten evaluation items are randomization, allocation concealment of the control group and the intervention group, withdrawal case analysis, blind method, balance of limit comparison, fairness of research methods, integrity of outcome measurement, reliability of measurement methods, and correctness of statistical analysis methods. The total possible score is 26 points, and publications with more than 15 points are considered standard quality. The Cochrane Handbook for Systematic Reviews (7) was used to assess the bias of literatures. This was divided into three levels. Level A is considered "low possibility of bias", level B is "moderate possibility of bias", and level $\mathrm{C}$ is "high possibility of bias". Literatures with level B or above were included in this study. Literature quality and bias evaluation were performed independently by two experienced researchers. Any disagreements were resolved by discussion or consultation with a third 
researcher.

\section{Data extraction}

The full text articles were reviewed and relevant data were collated and analyzed, including author, publication year, number of samples, grouping and grouping methods, number of groups, intervention measures, and outcome indicators.

\section{Statistical methods}

The Revman 5.3 software was used to analyze all statistical data. Literature heterogeneity was assessed using $\mathrm{I}^{2}$ analysis and $\mathrm{Q}$ verification. Results were considered heterogeneity when $\mathrm{I}^{2}>50 \%$ or $\mathrm{P}<0.1$, and the random effects model was used, otherwise the fixed effects model was used. Binary variables were expressed using odds ratio (OR) values with $95 \%$ confidence intervals $(\mathrm{CI})$, and $\mathrm{P}<0.05$ was considered statistically significant. The effect values were presented in forest plots. If there is heterogeneity among literatures, sensitivity analysis was used to detect the source of heterogeneity. Funnel plots were used to represent publication bias.

\section{Results}

\section{Literature screening results}

A total of 345 literatures (155 from PubMed, 45 from Ovid Medline, 66 from the Cochrane Library, and 79 from Embase) were initially screened in this study. After reviewing the abstracts and removing the literatures with inconsistent literature types, non-conforming study subjects, non-conforming intervention methods, and missing outcome measures, there were 21 publications remaining for literature quality and bias evaluation. The articles with JBI scores less than 15 and bias level less than level C were excluded. Finally, 11 literatures were included in this metaanalysis (Figure 1). The basic characteristics and evaluation of the literatures are shown in Table 1.

\section{Meta-analysis results}

The effects of extubation at 6 hours post-operation and immediately after the operation on urinary retention and UTI rate

A total of two literatures reported the urinary retention and
UTI rate in patients who were extubated immediately after the operation and in patients who were extubated at 6 hours after the operation. There was homogeneity in the results relating to both urinary retention and UTI $\left(\mathrm{I}^{2}=0 \%\right.$ and $\mathrm{P}=0.61$; and $\mathrm{I}^{2}=0 \%$ and $\mathrm{P}=0.98$, respectively). Analysis using the fixed-effects model showed that there was no statistical difference in the occurrence of UTI between extubation at 6 hours and immediately after the operation $(\mathrm{OR}=1.66$; $95 \%$ CI: 0.58 to $4.81 ; \mathrm{P}=0.35$; Figure 2). However, the probability of urinary retention in patients who were extubation at 6 hours post-operation was significantly lower than that patients who had immediate extubation (OR $=0.06$; $95 \%$ CI: 0.01 to $0.36 ; \mathrm{P}=0.002$; Figure 3 ).

\section{The effects of extubation at 12 hours post-operation compared to immediate after the operation on urinary retention and UTI rate}

A total of 3 studies examined patients who were extubated 12 hours postoperatively and patients who were extubated immediately post-surgery. All 3 literatures reported the rate of UTI after extubation, but only 2 reported the rate of urinary retention. The results from the literatures showed homogeneity for both indicators $\left(\mathrm{I}^{2}=0 \%\right.$ and $\mathrm{P}=0.84$; and $\mathrm{I}^{2}=0 \%$ and $\mathrm{P}=0.67$, respectively) and the fixed effects model was used. The UTI rate in patients who were extubated at 12 hours after surgery was significantly higher than that of patients who were extubated immediately after surgery (OR $=2.32 ; 95 \% \mathrm{CI}$ : 1.31 to $4.10 ; \mathrm{P}=0.004$; Figure 4). However, the probability of urinary retention in patients who were extubated at 12 hours after surgery was significantly lower than that of patients who were extubated immediately (OR $=0.18$; $95 \%$ CI: 0.04 to 0.83 ; $\mathrm{P}=0.03$; Figure 5).

\section{The effects of extubation 24 hours postoperatively and} immediate extubation on urinary retention and UTI rate A total of 4 literatures compared extubation immediately after the operation with extubation 24 hours postoperatively. The literatures presented homogeneity in terms of UTI $\left(\mathrm{I}^{2}=0 \%\right.$ and $\mathrm{P}=0.72)$ and urinary retention rate $\left(\mathrm{I}^{2}=0 \%\right.$ and $\left.\mathrm{P}=0.75\right)$. The fixed effects model demonstrated that the UTI rate associated with extubation at 24 hours post-operation was significantly higher than that of extubation immediately after the operation ( $\mathrm{OR}=4.51 ; 95 \% \mathrm{CI}: 2.02$ to $10.09 ; \mathrm{P}=0.0002$; Figure 6), while the probability of urinary retention related to extubation at 24 hours post-operation was significantly lower than that of extubation immediately post-operation (OR $=0.06,95 \%$ CI: 0.01 to $0.32 ; \mathrm{P}=0.001 ;$ Figure 7 ). 


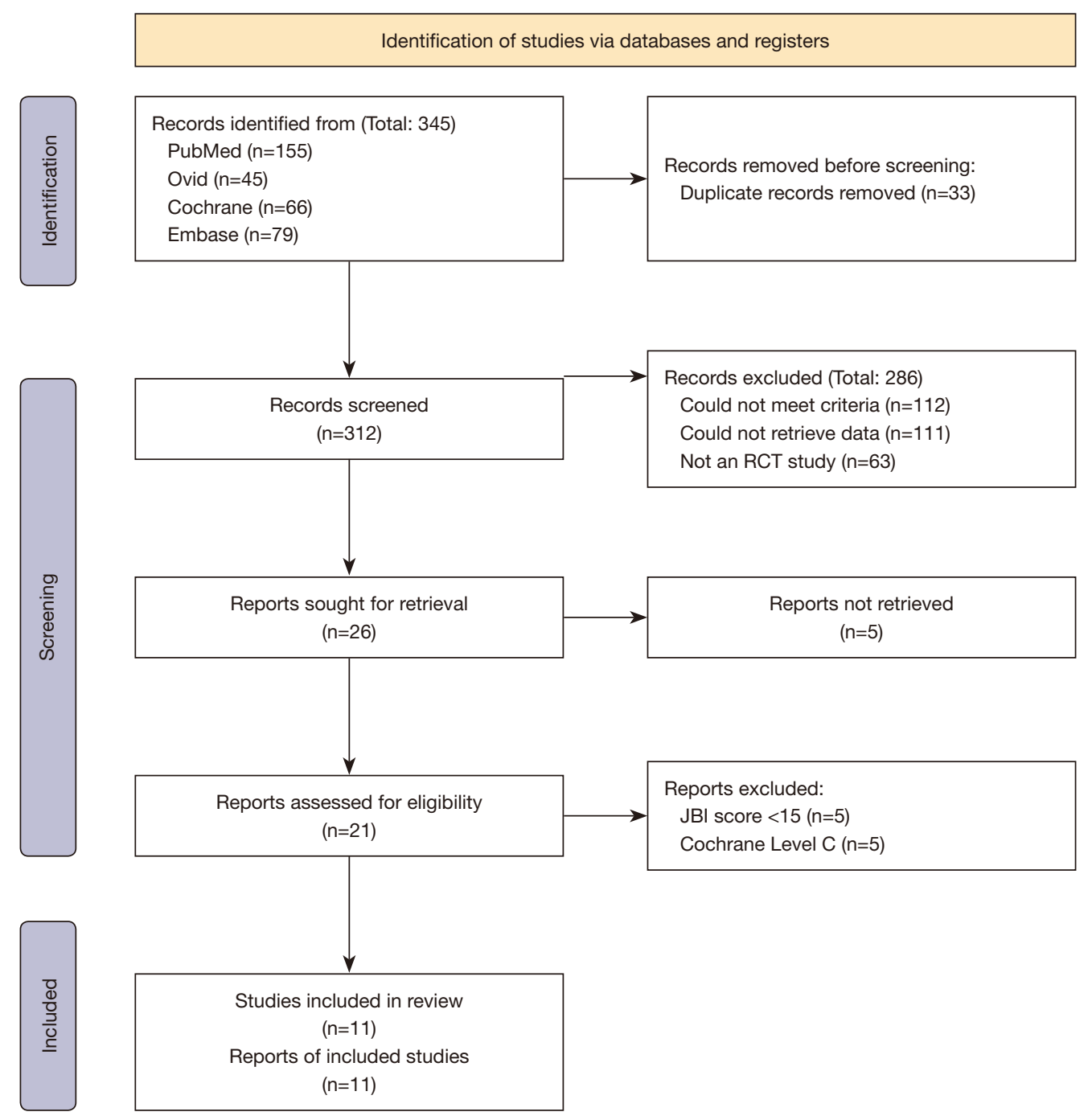

Figure 1 A flow chart showing the literature retrieval process.

\section{The effects of extubation 48 hours postoperatively and extubation 24 hours postoperatively on urinary retention and UTI rate}

In this study, three literatures compared extubation at 48 and 24 hours after the operation. Meta-analysis showed that the literature presented homogeneity in terms UTI rate $\left(\mathrm{I}^{2}=0 \% ; \mathrm{P}=0.72\right)$ and urinary retention rate analysis $\left(\mathrm{I}^{2}=0 \% ; \mathrm{P}=0.64\right)$. The fixed effects model demonstrated that the UTI rate in patients who were extubated at 48 hours after surgery was not significantly different from patients who were extubated at 24 hours after surgery $(\mathrm{OR}=1.62 ; 95 \%$ CI: 0.76 to $3.45 ; \mathrm{P}=0.21$; Figure 8$)$, and the probability of urinary retention was not significantly different between extubation at 48 hours and 24 hours after surgery $(\mathrm{OR}=0.28 ; 95 \% \mathrm{CI}$ : 0.07 to $1.18 ; \mathrm{P}=0.08$; Figure 9).

\section{Sensitivity analysis and bias analysis}

As the above literatures showed homogeneity in the analysis, no subsequent heterogeneity investigation was conducted. The sensitivity analysis was performed by change the fixed-effects model to random-effects model, which showed nearly the same results, and indicating the results were stable. In addition since the data size of the included literatures in each analysis was less than 4 , no bias analysis was performed. 


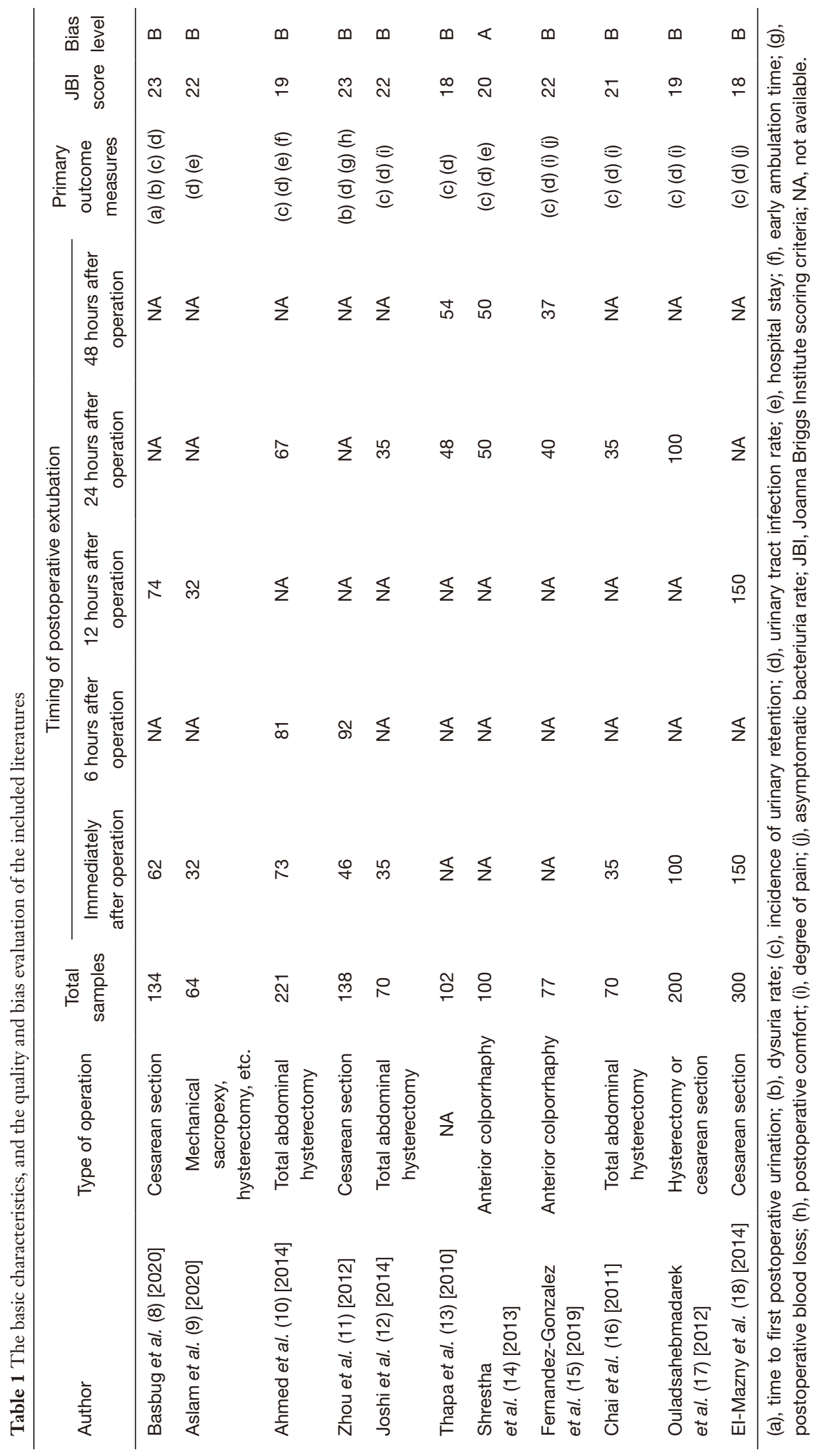




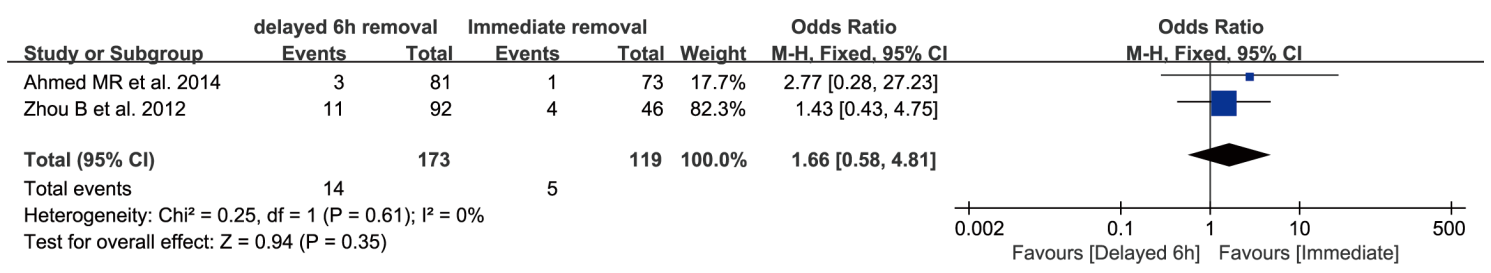

Figure 2 A comparison of the incidence of urinary tract infection between patients who were extubation at 6 hours post-surgery and patients who were extubation immediately after the operation.

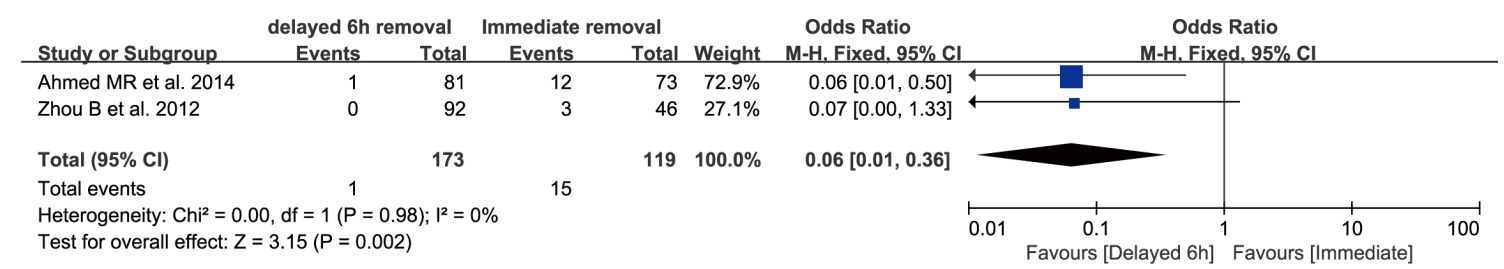

Figure 3 A comparison of the urinary retention rate between patients who were extubation at 6 hours post-surgery and patients who were extubation immediately after the operation.

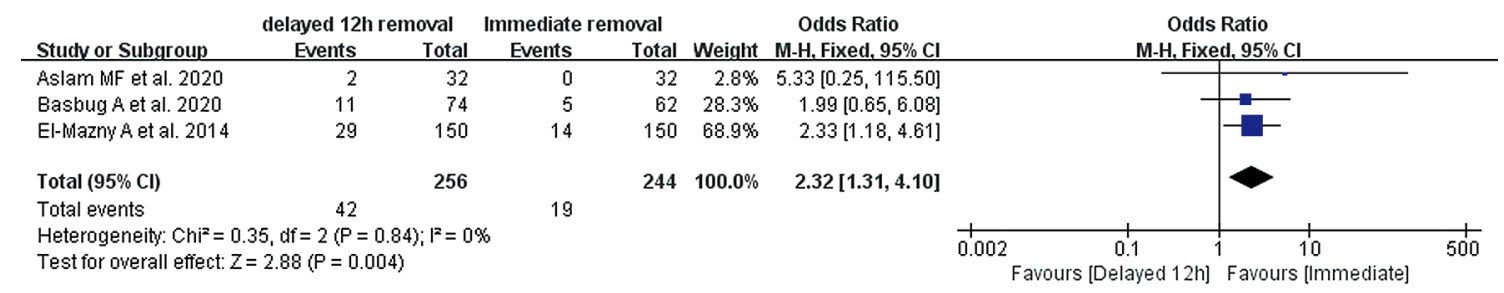

Figure 4 A comparison of the urinary tract infection rate between extubation at 12 hours after the operation and extubation immediately after the operation.

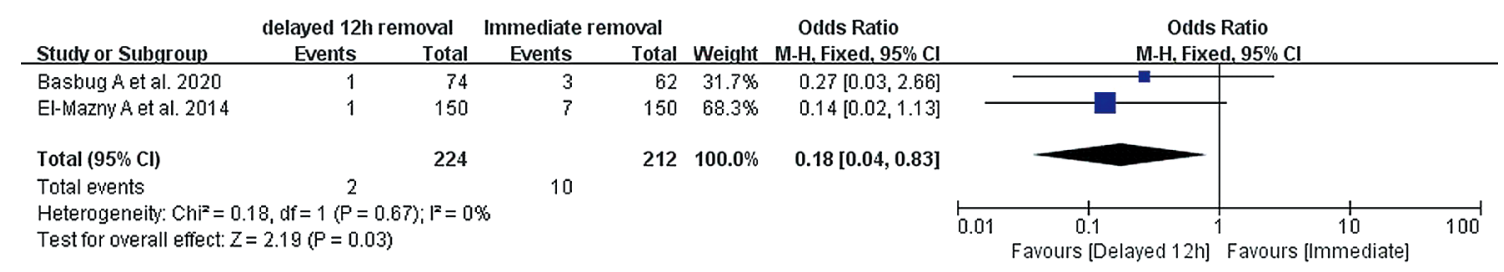

Figure 5 A comparison of the urinary retention rate between extubation at 12 hours after the operation and extubation immediately after the operation.

\section{Discussion}

The timing of urethral tube removal after gynecological and obstetric surgery has been controversial, and some studies (8) suggested that immediate postoperative catheter removal can shorten the time for patients to get out of bed for the first time and reduce the length of hospital stays. However, other reports (9) have suggested that there is no significant difference in the occurrence of urology-related complications between immediate postoperative extubation and extubation 12 hours after surgery. This current investigation is a systematic review of evidence-based medicine to determine the optimal catheter removal time.

A total of 11 literatures published since 2010 were included in this report. The meta-analysis demonstrated 


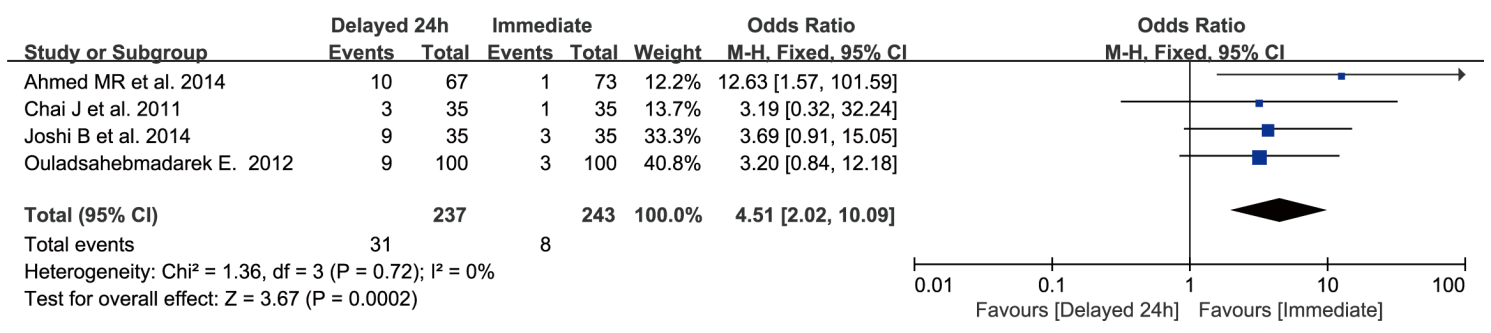

Figure 6 A comparison of the urinary tract infection rate between extubation at 24 hours after operation and extubation immediately after the operation.

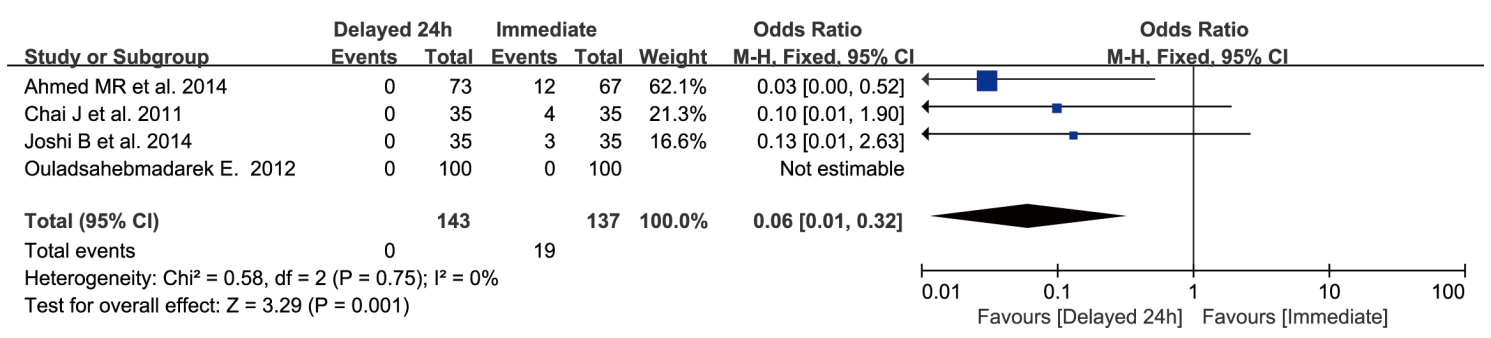

Figure 7 A comparison of the urinary retention rate between extubation at 24 hours after the operation and extubation immediately after the operation.

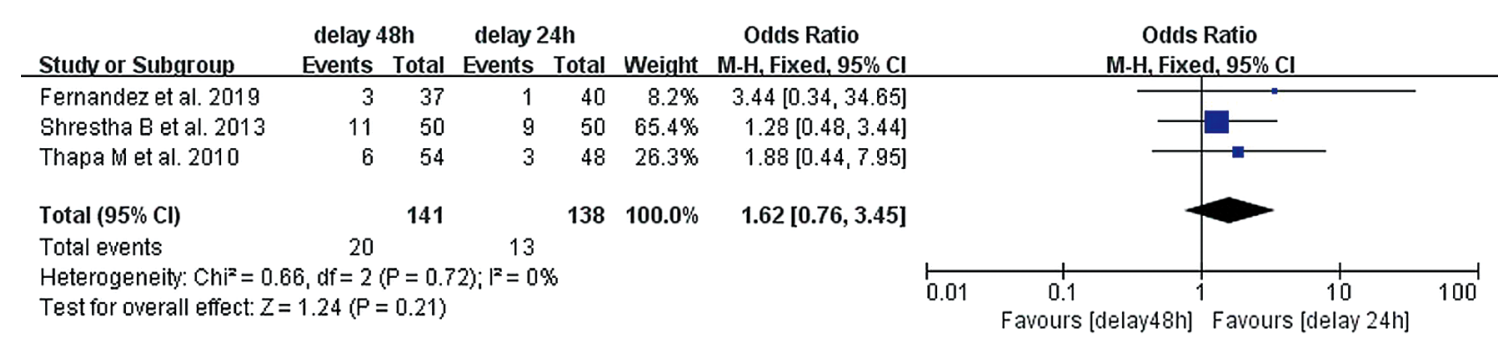

Figure 8 A comparison of the urinary tract infection rate between extubation at 24 hours after the operation and extubation at 48 hours after the operation.

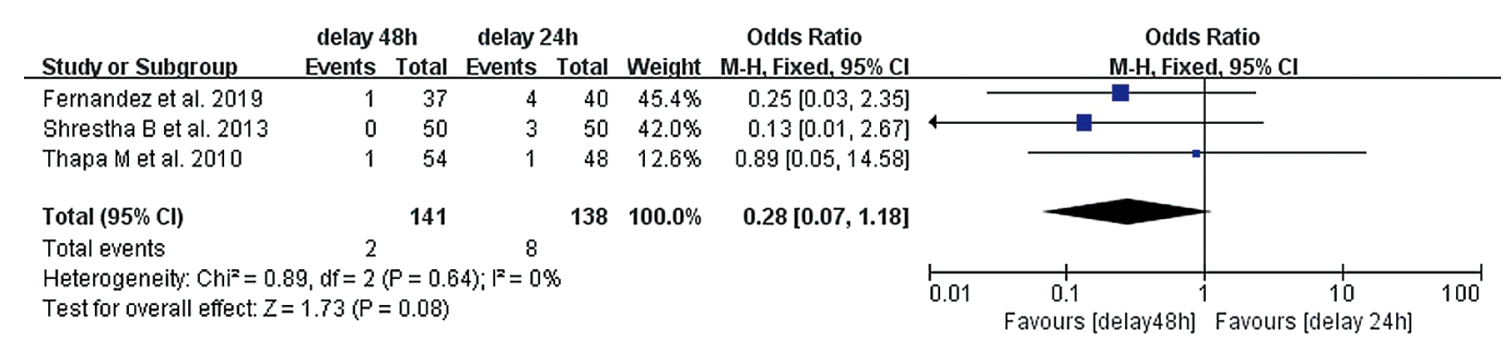

Figure 9 A comparison of the urinary retention rate between extubation at 24 hours after the operation and extubation at 48 hours after the operation. 
that the rate of UTI was not significantly increased when the catheter was removed 6 hours after surgery compared with extubation immediately after surgery, but the urinary retention rate was significantly reduced. However, the rate of UTI was increased when the catheter was removed 24 hours after surgery compared with immediate extubation, and the urinary retention rate was further reduced. The UTI and urinary retention rates were comparable between patients who were extubated 48 hours postoperatively and those who were extubated 24 postoperatively.

The above results revealed that the probability of UTI in patients increases with time, which is consistent with the observations of Chen et al. (19). As an invasive foreign body, urinary catheters provide a channel for microorganisms to enter the bladder from outside the body. In addition, the wet intravesical environment facilitates the colonization of microorganisms. With the extension of time, the positive rate of urine microorganisms increases, and the risk of symptomatic infection also increases (20). The metaanalysis showed that the incidence of urinary retention decreased with time, and the possibility of urinary retention was highest in patients who were extubated immediately after surgery. This may be due to the lingering effects of the anesthetic on the bladder urinating muscles after surgery. Thus, extubation immediately after surgery may increase the risk of urinary retention and dysuria (21). However, with the passage of time, bladder function and voiding function tend to recover, and the catheter should be removed to avoid increasing the risk of UTIs. In this study, extubation at 6 hours after the operation did not increase the UTI rate, but the urinary retention rate was statistically different from immediate extubation, suggesting that extubation at 6 hours after the operation is the optimal timeframe.

The retention time of urinary catheter after different operations is different. The removal time of the catheter should fully consider the recovery of bladder function and urinary control ability of the patient during anesthesia awakening, so as to ensure that the patient can urinate smoothly after extubation (22). We believe that $6 \mathrm{~h}$ after gynecological and obstetric surgery is scientific, because patients need 3-5 hours to recover perception from epidural anesthesia, and their bladder function would recover about 6 hours after operation from our experience, so the catheter can be removed 6 hours after operation.

There were some limitations to this study. The number of included literatures was small and funnel plots could not be drawn to assess publication bias. Since there was homogeneity among the articles, some heterogeneous factors (such as different types of surgery) may not have been considered. Due to non-uniform result indicators reported in the literatures, meta-analysis could not be performed for indicators such as length of hospital stay, bacteriuria rate, degree of pain, time to first ambulation, and fever rate, which may have caused bias in the conclusions. Future studies involving larger sample sizes and more comprehensive outcome indicators are warranted to verify the optimal timing for postoperative catheter removal in patients undergoing gynecological and obstetric surgery.

\section{Conclusions}

This meta-analysis, involving 11 articles, revealed that the optimal timing for postoperative catheter removal in patients undergoing gynecological and obstetric surgery is 6 hours after surgery.

\section{Acknowledgments}

Funding: None.

\section{Footnote}

Reporting Checklist: The authors have completed the PRISMA reporting checklist. Available at https://dx.doi. org/10.21037/apm-21-3290

Conflicts of Interest: Both authors have completed the ICMJE uniform disclosure form (available at https://dx.doi. org/10.21037/apm-21-3290). The authors have no conflicts of interest to declare.

Ethical Statement: The authors are accountable for all aspects of the work in ensuring that questions related to the accuracy or integrity of any part of the work are appropriately investigated and resolved.

Open Access Statement: This is an Open Access article distributed in accordance with the Creative Commons Attribution-NonCommercial-NoDerivs 4.0 International License (CC BY-NC-ND 4.0), which permits the noncommercial replication and distribution of the article with the strict proviso that no changes or edits are made and the original work is properly cited (including links to both the formal publication through the relevant DOI and the 
license). See: https://creativecommons.org/licenses/by-nc$\mathrm{nd} / 4.0 /$.

\section{References}

1. Zaouter C, Wuethrich P, Miccoli M, et al. Early removal of urinary catheter leads to greater post-void residuals in patients with thoracic epidural. Acta Anaesthesiol Scand 2012;56:1020-5.

2. Long A, Edwards J, Thompson R, et al. A clinical evaluation of a sensor to detect blockage due to crystalline biofilm formation on indwelling urinary catheters. BJU Int 2014;114:278-85.

3. Schauer I, Al-Ali BM, Lüftenegger W, et al. Is there a place for indwelling transurethral catheterization in women with febrile urinary tract infection? A prospective randomized trial. World J Urol 2019;37:849-52.

4. Toprak T, Sahin A, Kutluhan MA, et al. Does duration of stenting increase the risk of clinical infection? Arch Ital Urol Androl 2020;91:237-40.

5. Hooton TM, Bradley SF, Cardenas DD, et al. Diagnosis, prevention, and treatment of catheter-associated urinary tract infection in adults: 2009 International Clinical Practice Guidelines from the Infectious Diseases Society of America. Clin Infect Dis 2010;50:625-63.

6. Tyson AF, Campbell EF, Spangler LR, et al. Implementation of a Nurse-Driven Protocol for Catheter Removal to Decrease Catheter-Associated Urinary Tract Infection Rate in a Surgical Trauma ICU.J Intensive Care Med 2020;35:738-44.

7. Huang H, Dong L, Gu L. The timing of urinary catheter removal after gynecologic surgery: A meta-analysis of randomized controlled trials. Medicine (Baltimore) 2020;99:e18710.

8. Basbug A, Yuksel A, Ellibeş Kaya A. Early versus delayed removal of indwelling catheters in patients after elective cesarean section: a prospective randomized trial. J Matern Fetal Neonatal Med 2020;33:68-72.

9. Aslam MF, Bazzi AA, Hagglund KH, et al. When to Remove the Indwelling Catheter After Minimally Invasive Sacrocolpopexy? CARESS (CAtheter REmoval after Sacrocolpopexy Surgery). Female Pelvic Med Reconstr Surg 2020;26:120-7.

10. Ahmed MR, Sayed Ahmed WA, Atwa KA, et al. Timing of urinary catheter removal after uncomplicated total abdominal hysterectomy: a prospective randomized trial. Eur J Obstet Gynecol Reprod Biol
2014;176:60-3.

11. Zhou B, Lin Z, Huang Y. Effect of extubation time of indwelling urinary catheters on postoperative recovery after cesarean section. Nan Fang Yi Ke Da Xue Xue Bao 2012;32:1221-2.

12. Joshi B, Aggarwal N, Chopra S, et al. A prospective randomized controlled comparison of immediate versus late removal of urinary catheter after abdominal hysterectomy. J Midlife Health 2014;5:68-71.

13. Thapa M, Shrestha J, Pradhan BN, et al. Bacteriuria and urinary retention following gynaecological surgery: comparing short vs long term catheterization. J Nepal Health Res Counc 2010;8:107-9.

14. Shrestha B, Marhatha R, Kayastha S, et al. Short-term versus long-term catheterization after vaginal prolapse surgery. Nepal Med Coll J 2013;15:102-5.

15. Fernandez-Gonzalez S, Martinez Franco E, Martínez-Cumplido R, et al. Reducing postoperative catheterisation after anterior colporrhaphy from 48 to 24 h: a randomised controlled trial. Int Urogynecol J 2019;30:1897-902.

16. Chai J, Pun TC. A prospective randomized trial to compare immediate and 24-hour delayed catheter removal following total abdominal hysterectomy. Acta Obstet Gynecol Scand 2011;90:478-82.

17. Ouladsahebmadarek E, Sayyah- Melli M, Jafari- Shobeiri M. A. Randomized clinical trial to compare immediate versus delayed removal of foley catheter following abdominal hysterectomy and laparotomy. Pak J Med Sci 2012;28:380-3.

18. El-Mazny A, El-Sharkawy M, Hassan A. A prospective randomized clinical trial comparing immediate versus delayed removal of urinary catheter following elective cesarean section. Eur J Obstet Gynecol Reprod Biol 2014;181:111-4.

19. Chen YY, Chi MM, Chen YC, et al. Using a criteria-based reminder to reduce use of indwelling urinary catheters and decrease urinary tract infections. Am J Crit Care 2013;22:105-14.

20. Fink R, Gilmartin H, Richard A, et al. Indwelling urinary catheter management and catheter-associated urinary tract infection prevention practices in Nurses Improving Care for Healthsystem Elders hospitals. Am J Infect Control 2012;40:715-20.

21. Marschall J, Carpenter CR, Fowler S, et al. Antibiotic prophylaxis for urinary tract infections after removal of urinary catheter: meta-analysis. BMJ 
2013;346:f3147.

22. Vallverdú Vidal M, Barcenilla Gaite F. Antiseptic urinary catheterization and maintenance of the bladder catheter.
Med Intensiva (Engl Ed) 2019;43 Suppl 1:48-52.

(English Language Editor: J. Teoh)

Cite this article as: Liao X, Xie L. A systematic review and meta-analysis of the timing of indwelling catheter extubation in patients undergoing gynecological and obstetric surgery. Ann Palliat Med 2021;10(12):12519-12528. doi: 10.21037/apm-21-3290 